\title{
The Design and Fabrication of the Savannah River Technology Center's New Glovebox Contained Scanning Electron Microscope
}

\author{
Michael E. Summer
}

\author{
Westinghouse Savannah River Site, Analytical Development Section, \\ 773-A Room C-136, Aiken, SC 29808
}

The Savannah River Technology Center has analyzed radioactive contaminated samples using a glovebox contained scanning electron microscopy for over 18 years. Since then the advances in microscope and detector technology has greatly improved. A new LEO 440 scanning electron microscope was contained within a newly designed glovebox.

Many factors must be considered when containing an Electron Microscope within a glovebox. A very important factor to consider is "what tasks will be the most repetitive". One task most often preformed is changing of samples. A door, which slides out on rails will strike the containment wall before opening all of the way, and will block ones view when looking into the chamber. Other microscope vendors doors swing open, but the sample holder is inside the chamber, which makes exchanging samples more difficult. Therefore, a microscope chamber having a swing-out door with the stage attached is the most desirable.

Another factor to consider is how to reach the areas of highest maintenance. Changing the filament is the highest maintenance to be performed. Therefore, our glovebox was made with 45 degree angles on top so that glass panels with gloveports could be installed to better reach the top of the column. Also, a glass panel was installed on top of the glovebox roof, so that the column liner could be reinstalled with greater ease. Another maintenance item to consider is the exchange of components, or accessories. In order to change the turbo pump with greater ease, the lower portion of one side of the glovebox was made to incorporate a glovebag. This will enable much greater freedom of motion to reach the bolts of the pump. Also, make bagout ports large enough that will allow the removal of pumps or detectors. Our gloveboxes incorporate a 12" port for removing the turbo pump. A 16" and 20"port for the removal of carbon or gold coaters, and EDS, WDS detectors.

A new plinth was built to remove the electronics from under the microscope, therefore cables were lengthened to reach the glovebox. Cables were increased from their standard cable length plus an additional 26 feet. To make a safe connection through the glovebox wall, pavemate connectors were used via a bulkhead connector plate to hermetically seal the connectors. To retain a clean signal some cables could not be split therefore the ROXTEX cable sealing system was used.

Illustrations of features will be shown between the old microscope versus the new microscope as well as Glovebox Design changes that have been implemented for better operation and maintenance ergonomics.

References

[1.] This project was supported by the Department of Energy under Task TSD-LOE-97-00950. 


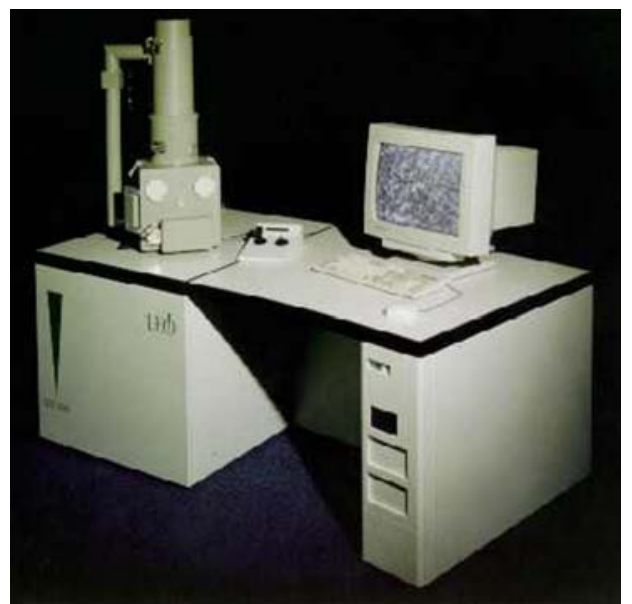

Fig. 1 LEO 440

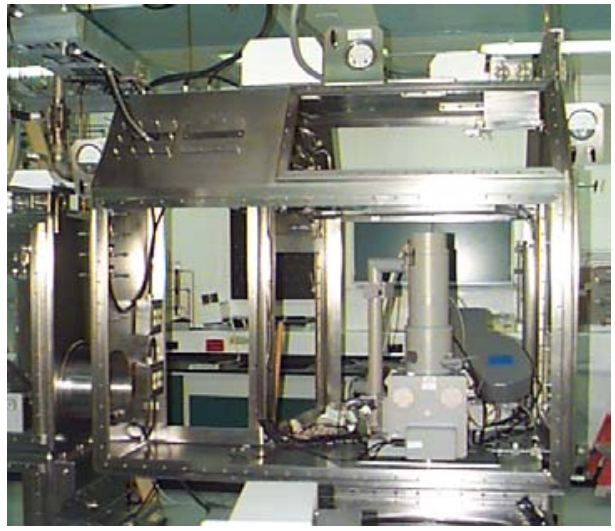

Fig. 3 LEO 440 Glovebox

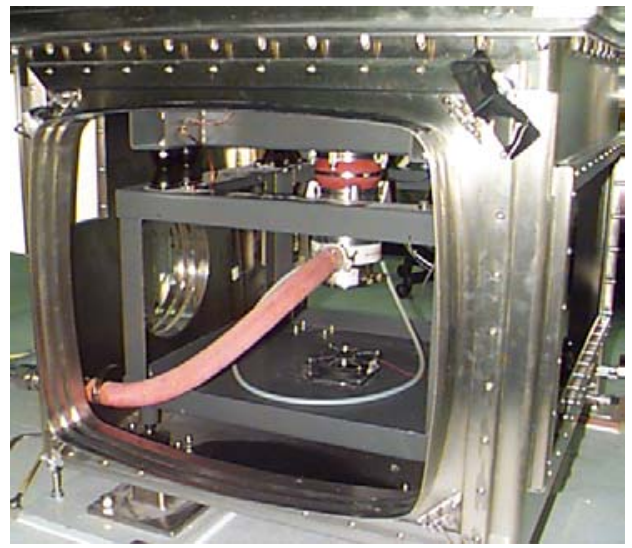

Fig. 5 Plinth After Removal

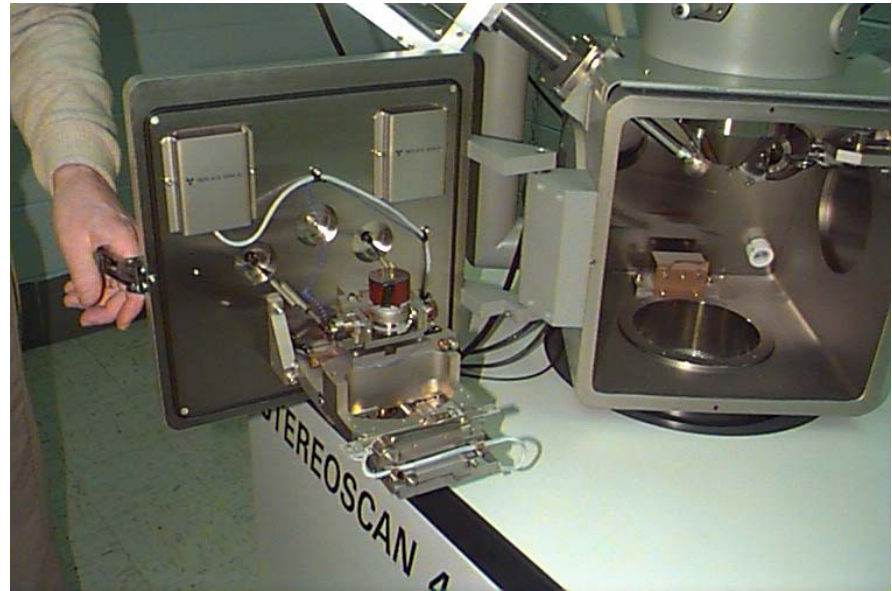

Fig. 2 Sample Stage on Door

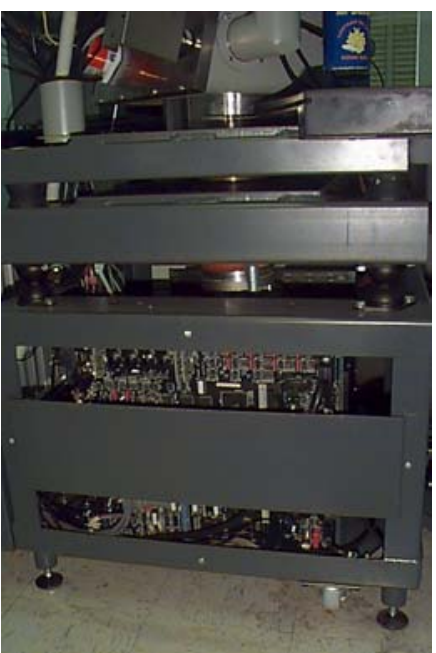

Fig. 4 Plinth Before Electronics Removal

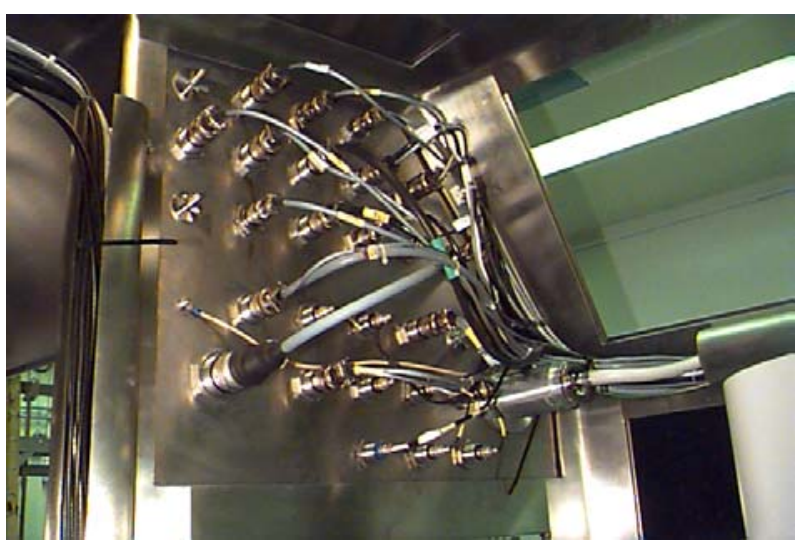

Fig. 6 Pavement Connectors 